\title{
Proposition of a Tool to Adjust the Inspired Oxygen Fraction in Anesthesia Devices during Prolonged Mechanical Ventilation in COVID-19 Patients
}

\author{
Plínio de Oliveira Holanda ${ }^{1,2 *}{ }^{*}$, Nely Marjollie Guanabara Teixeira Reis ${ }^{1,3}$, \\ José Carlos R. Nascimento ${ }^{1,2,4}$, Felipe Paiva Alencar ${ }^{5}$, Marilman Maciel Benício ${ }^{1}$ \\ ${ }^{1}$ Department of Anesthesia, Dr. Jose Frota Institute, Fortaleza, Brazil \\ ${ }^{2}$ Unichristus University, Fortaleza, Brazil \\ ${ }^{3}$ Department of Anesthesia, Fortaleza General Hospital, Fortaleza, Brazil \\ ${ }^{4}$ Laboratory of the Biology of Tissue Healing, Ontogeny and Nutrition, Department of Morphology and Institute of Biomedicine, \\ School of Medicine, Federal University of Ceara, Fortaleza, Brazil \\ ${ }^{5}$ Department of Computer Engineering, Ceara State University, Fortaleza, Brazil \\ Email: *anesthesiaceara@gmail.com
}

How to cite this paper: de Oliveira Holanda, P., Reis, N.M.G.T., Nascimento, J.C.R., Alencar, F.P. and Benício, M.M. (2021) Proposition of a Tool to Adjust the Inspired Oxygen Fraction in Anesthesia Devices during Prolonged Mechanical Ventilation in COVID-19 Patients. Open Journal of Anesthesiology, 11, 299-305. https://doi.org/10.4236/ojanes.2021.1110029

Received: September 18, 2021

Accepted: October 16, 2021

Published: October 19, 2021

Copyright $\odot 2021$ by author(s) and Scientific Research Publishing Inc. This work is licensed under the Creative Commons Attribution International License (CC BY 4.0).

http://creativecommons.org/licenses/by/4.0/ (c) (i) Open Access

\begin{abstract}
The COVID-19 pandemic has had a major impact on health care services, leading to a breakdown in public and private health systems worldwide. A major challenge was the scarcity of mechanical ventilators, which resulted in the use of anaesthesia devices for this purpose. However, they are quite different from mechanical ventilators used in Intensive Care Units and some adaptations, such as the use of high flow to reduce $\mathrm{CO}_{2}$ rebreathing, were necessary to ensure patient safety. The objective of this study was to present a mathematical formula and develop a tool that can be used to adjust the flow of oxygen and air in flow metres of anaesthesia devices that do not have oxygen analysers or these analysers are not operational. A literature review was conducted using the main health databases and libraries as research sources: PubMed, Virtual Health Library (VHL), SciELO, and Cochrane. The review included studies published in English, Spanish, and Portuguese. Animal studies were excluded. A total of 11 references were included to support this article.
\end{abstract}

\section{Keywords}

Anaesthesia Ventilator, Intensive Care Unit, $\mathrm{FiO}_{2}$, Fresh Gas Flow, Webpage 


\section{Introduction}

The COVID-19 pandemic has had a major impact worldwide. The lack of mechanical ventilators in different parts of the world resulted in the need to use anaesthesia devices to provide ventilatory support for COVID-19 patients [1] [2]. As anaesthesia mechanical ventilators work differently from the mechanical ventilators used in intensive care units (ICU) and health professionals in this area do not routinely work with these devices, their improper use can result in serious consequences for the patient, such as hypercapnia and hypoxia [3] [4] [5].

One of the difficulties observed in the use of this equipment is how to determine the fraction of inspired oxygen $\left(\mathrm{FiO}_{2}\right)$, since many anaesthesia devices have no specific mechanisms (oxygen analyser) for determining this fraction. Another common difficulty occurs in some multiparametric monitors: they often do not have any gas analyser or they just have capnography incorporated in their system. This study emphasises that these two devices should always be present, and that no mathematical formula will replace them [6].

$\mathrm{FiO}_{2}$ calculation is only one of the challenges that may be encountered when using some anaesthesia devices as mechanical ventilators in the ICU. The adequate adjustment of ventilatory parameters is of paramount importance for the treatment of patients on ventilatory support, whether due to COVID-19 or not, and its improper adjustment can be dangerous [3] [5]. Due to the scarcity of studies addressing the topic of $\mathrm{O}_{2}$ and air flow measurement based on $\mathrm{FiO}_{2}$ and total fresh gas flow (FGF), the objective of this study is to present a mathematical calculation and develop a tool that would allow the quick and precise adjustment of these parameters, considering the recommendations for the use of high flow when anaesthesia devices are used in the ICU [7].

\section{Methods}

A literature review was conducted using the main health databases and libraries including PubMed, Virtual Health Library (VHL), SciELO, and Cochrane as research sources. The review included studies published in English, Spanish, and Portuguese. Animal studies were excluded. These studies were analysed and summarized by pairs.

\section{Results}

A total of 11 references were included to support this article. Most of these references were published only online due to the pandemic and its rapid onset. Some references are considerations for the use of anaesthesia machines as ICU ventilators in case of shortage of these machines.

\section{Discussion}

\section{Use of anaesthesia machines for long periods}

The use of anaesthesia devices for a long period revealed the need to fre- 
quently replace the $\mathrm{CO}_{2}$ absorber due to its rapid saturation [1]. This replacement can lead to problems such as the possibility of depleting the stocks of $\mathrm{CO}_{2}$ absorbers and the need to stop mechanical ventilation for replacement, leading to a higher risk of contamination for the medical staff. In addition, there is a risk of incorrect assembly or even rupture of the canister. This would require its replacement, which is sometimes impossible since another canister may not readily be available [8] [9].

There is no consensus on the ideal FGF since these devices were not developed to be used for several days. High FGF would reduce the use of $\mathrm{CO}_{2}$ absorbers and would prevent the risk of hypercapnia due to $\mathrm{CO}_{2}$ rebreathing. Some anaesthesia device manufacturers recommended an FGF greater than or equal to $150 \%$ of patient's minute volume and another one recommends at least $100 \%$ of the patient minute volume. It is important to remember that the use of humidifying and heating filters is essential, since the use of a high FGF tends to lead to drier and not heated inhaled gases [2].

The minute volume (VE) is not always fixed as it depends on the depth of sedation and muscle relaxation. In the operating room, the degree of muscle relaxation and sedation seems to be more tightly controlled by the anaesthetist and $\mathrm{VE}$ is usually fixed since mandatory ventilation is more frequently used. However, in the ICU department the degree of muscle relaxation and sedation does not seem to be so tightly controlled and VE can vary more frequently [7]. Some patients exceed the preestablished volume and, therefore, a trained health professional need to reset it. In most anaesthesia machines, the volume- or pressure-controlled ventilation modes are mandatory modes and use an adjustable FGF determined by the operator due to the absence of a trigger, unlike ICU ventilators, which have a trigger in these ventilation modes. These are, in fact, assisted-controlled modes in ICU [10].

However, despite these recommendations, there is still no solution for FGF management in anaesthesia devices when they are used as ICU ventilators in fully controlled modes in cases of asynchrony, which are not uncommon in this hospital department. So, we do not recommend using anaesthesia machines as mechanical ventilators in ICU, but we know they were used like this during the COVID-19 pandemic as only a few hospitals had enough mechanical ventilators for such a large number of patients. As an example, in circular system this formula can be imprecise [11].

Considering that many anaesthesia machines do not allow the accurate control of the desired $\mathrm{FiO}_{2}$, it is important to calculate the necessary $\mathrm{O}_{2}$ and air flow to determine this $\mathrm{FiO}_{2}$ when adjusting anaesthesia ventilators [6]. The formula is very useful for anaesthesia machines without an oxygen analyser or with a malfunctioning one. In these cases, it would be possible to estimate $\mathrm{FiO}_{2}$ by making the ideal mixture of $\mathrm{O}_{2}$ and air. The formula published here has only two variables: $\mathrm{FiO}_{2}$ and total flow. These are used to determine the flow of one gas and, subsequently, determine the flow of another gas by subtracting the total flow (Appen- 
dix). This formula is a simple mathematical calculation and Appendix explains it.

\section{$\mathrm{FiO}_{2}$ adjustment tool}

The authors designed a webpage to facilitate the calculation of oxygen and compressed air flow to obtain the desired $\mathrm{FiO}_{2}$. The page was developed in HTML, CSS, and JavaScript, the most used web development technologies. In addition, the Bootstrap Library was used to assist in the development and ensure a design like the one used in most mobile devices. Access can be obtained using this link: https://alencar-felipe.github.io/o2-flow. $\mathrm{O}_{2}$ and air flows are obtained by filling the two fields with $\mathrm{FiO}_{2}$ and total flow. A table was included to be used as a general guide when it is impossible to access the webpage (Table 1).

\section{Conclusion}

There is currently no intention of replacing ICU ventilators with anaesthesia devices, as they were not built for this purpose and we know in circular system this

Table 1. Air and $\mathrm{O}_{2}$ flow-anaesthesia device.

\begin{tabular}{|c|c|c|c|c|c|c|c|c|c|c|c|c|c|c|c|}
\hline $\mathrm{FiO}_{2}$ & $\mathrm{~F}_{\text {tot }}$ & $\mathrm{FO}_{2}$ & $\mathrm{~F}_{\mathrm{air}}$ & $\mathrm{FIO}_{2}$ & $\mathrm{~F}_{\text {tot }}$ & $\mathrm{FO}_{2}$ & $\mathrm{~F}_{\mathrm{air}}$ & $\mathrm{FiO}_{2}$ & $F_{\text {tot }}$ & $\mathrm{FO}_{2}$ & $\mathrm{~F}_{\mathrm{air}}$ & $\mathrm{FiO}_{2}$ & $\mathrm{~F}_{\text {tot }}$ & $\mathrm{FO}_{2}$ & $\mathrm{~F}_{\text {air }}$ \\
\hline 0.3 & 4 & 0.46 & 3.54 & 0.5 & 4 & 1.47 & 2.53 & 0.7 & 4 & 2.48 & 1.52 & 0.9 & 4 & 3.49 & 0.51 \\
\hline 0.3 & 5 & 0.57 & 4.43 & 0.5 & 5 & 1.84 & 3.16 & 0.7 & 5 & 3.10 & 1.90 & 0.9 & 5 & 4.37 & 0.63 \\
\hline 0.3 & 6 & 0.68 & 5.32 & 0.5 & 6 & 2.20 & 3.80 & 0.7 & 6 & 3.72 & 2.28 & 0.9 & 6 & 5.24 & 0.76 \\
\hline 0.3 & 7 & 0.80 & 6.20 & 0.5 & 7 & 2.57 & 4.43 & 0.7 & 7 & 4.34 & 2.66 & 0.9 & 7 & 6.11 & 0.89 \\
\hline 0.3 & 8 & 0.91 & 7.09 & 0.5 & 8 & 2.94 & 5.06 & 0.7 & 8 & 4.96 & 3.04 & 0.9 & 8 & 6.99 & 1.01 \\
\hline 0.3 & 9 & 1.03 & 7.97 & 0.5 & 9 & 3.30 & 5.07 & 0.7 & 9 & 5.58 & 3.42 & 0.9 & 9 & 7.86 & 1.14 \\
\hline 0.3 & 10 & 1.14 & 8.86 & 0.5 & 10 & 3.67 & 6.33 & 0.7 & 10 & 6.20 & 3.80 & 0.9 & 10 & 8.73 & 1.27 \\
\hline 0.3 & 11 & 1.25 & 9.75 & 0.5 & 11 & 4.04 & 6.96 & 0.7 & 11 & 6.82 & 4.18 & 0.9 & 11 & 9.61 & 1.39 \\
\hline 0.3 & 12 & 1.37 & 10.63 & 0.5 & 12 & 4.41 & 7.59 & 0.7 & 12 & 7.44 & 4.56 & 0.9 & 12 & 10.48 & 1.52 \\
\hline 0.3 & 13 & 1.48 & 11.52 & 0.5 & 13 & 4.77 & 8.23 & 0.7 & 13 & 8.06 & 4.94 & 0.9 & 13 & 11.35 & 1.65 \\
\hline 0.3 & 14 & 1.59 & 12.41 & 0.5 & 14 & 5.14 & 8.86 & 0.7 & 14 & 8.68 & 5.32 & 0.9 & 14 & 12.23 & 1.77 \\
\hline 0.4 & 4 & 0.96 & 3.04 & 0.6 & 4 & 1.97 & 2.03 & 0.8 & 4 & 2.99 & 1.01 & & & & \\
\hline 0.4 & 5 & 1.20 & 3.80 & 0.6 & 5 & 2.47 & 2.53 & 0.8 & 5 & 3.73 & 1.27 & & & & \\
\hline 0.4 & 6 & 1.44 & 4.56 & 0.6 & 6 & 2.96 & 3.04 & 0.8 & 6 & 4.48 & 1.52 & & & & \\
\hline 0.4 & 7 & 1.68 & 5.32 & 0.6 & 7 & 3.46 & 3.54 & 0.8 & 7 & 5.23 & 1.77 & & & & \\
\hline 0.4 & 8 & 1.92 & 6.08 & 0.6 & 8 & 3.95 & 4.05 & 0.8 & 8 & 5.97 & 2.03 & & & & \\
\hline 0.4 & 9 & 2.16 & 6.84 & 0.6 & 9 & 4.44 & 4.56 & 0.8 & 9 & 6.72 & 2.28 & & & & \\
\hline 0.4 & 10 & 2.41 & 7.59 & 0.6 & 10 & 4.94 & 5.06 & 0.8 & 10 & 7.47 & 2.53 & & & & \\
\hline 0.4 & 11 & 2.65 & 8.35 & 0.6 & 11 & 5.43 & 5.57 & 0.8 & 11 & 8.22 & 2.78 & & & & \\
\hline 0.4 & 12 & 2.89 & 9.11 & 0.6 & 12 & 5.92 & 6.08 & 0.8 & 12 & 8.96 & 3.04 & & & & \\
\hline 0.4 & 13 & 3.13 & 9.87 & 0.6 & 13 & 6.42 & 6.58 & 0.8 & 13 & 9.71 & 3.29 & & & & \\
\hline 0.4 & 14 & 3.37 & 10.63 & 0.6 & 14 & 6.91 & 7.09 & 0.8 & 14 & 10.46 & 3.54 & & & & \\
\hline
\end{tabular}

Fraction of inspired $\mathrm{O}_{2}=\mathrm{FiO}_{2}$; Total fresh gas flow (FGF), $\mathrm{F}_{\text {tot }} ; \mathrm{O}_{2}$ flow, $\mathrm{FO}_{2}$; Compressed air flow, $\mathrm{F}_{\text {air }}$; Total flow always $>$ Minute volume; Total flow = Minute volume $\times 1.4$ (to maintain a safety margin). 
formula can be imprecise. However, in situations where there are shortages of mechanical ventilators, anaesthesia devices can be a valuable resource if used correctly. There is no guarantee that this situation will not reoccur in the future, but devices without resources like an oxygen analyser, can be the only available ventilator in less prepared environments. It must be stressed that all anaesthesia machines should have an oxygen analyser and it should be mandatory. The final objective of this study was to present a methodology for the calculation of $\mathrm{O}_{2}$ and air flow based on $\mathrm{FiO}_{2}$ and FGF and to develop a tool that safely adapts this flow to assist professionals (especially non-anaesthetists) who may need to operate these devices, which they do not routinely work with, in order to significantly increase patient safety. We must stress that we do not guarantee a precise $\mathrm{FiO}_{2}$ with this formula but it can be very useful in cases where anaesthesia machines need to replace mechanical ventilators. This happened during the Covid-19 pandemic.

\section{Acknowledgements}

1) Assistance with the article. None.

2) Financial support and sponsorship. None.

3) Presentation (for original articles only). None.

\section{Conflicts of Interest}

The authors declare no conflicts of interest regarding the publication of this paper.

\section{References}

[1] The New York Times (2020) There Aren't Enough Ventilators to Cope with the Coronavirus. https://www.nytimes.com/2020/03/18/business/coronavirus-ventilator-shortage.ht $\underline{\mathrm{ml}}$

[2] APSF and ASA (2020) APSF/ASA Guidance on Purposing Anesthesia Machines as ICU Ventilators.

https://www.asahq.org/in-the-spotlight/coronavirus-covid-19-information/purposi $\underline{\text { ng-anesthesia-machines-for-ventilators }}$

[3] Mora Carpio, A.L. and Mora, J.I. (2020) Ventilator Management. StatPearls Publishing, Treasure Island.

[4] Bristle, T.J., Collins, S., Hewer, I. and Hollifield, K. (2014) Anesthesia and Critical Care Ventilator Modes: Past, Present, and Future. AANA Journal, 82, 387-400.

[5] Sperl, K. and Jöhr, M. (2003) Elevated Inspiratory $\mathrm{CO}_{2}$ Concentrations Caused by the Design of an Anesthesia Machine. Acta Anaesthesiologica Scandinavica, 47, 496. https://doi.org/10.1034/j.1399-6576.2003.t01-8-00044.x

[6] Garg, R. and Gupta, R.C. (2013) Analysis of Oxygen, Anaesthesia Agent and Flows in Anaesthesia Machine. Indian Journal of Anaesthesia, 57, 481-488.

[7] Dosch, M. (2020) Using the Anesthesia Workstation as a Ventilator for Critically Ill Patients: Technical Considerations. AANA Journal, 6, 13-17.

[8] Torres, M.L.A., Canhisares, F.A.T., Quintão, V.C., et al. (2020) Management of $\mathrm{CO}_{2}$ 
Absorbent While Using the Anestesia Machine as a Mechanical Ventilator on Patients with COVID-19. Brazilian Journal of Anesthesiology, 70, 184-185.

https://doi.org/10.1016/j.bjane.2020.04.001

[9] Chen, Y.H., Chen, C.L., Chung, Y.T., Yeh, L.T., Lu, K.T. and Lin, C.Y. (2004) The Valid Time of Soda Lime Could Be Safely Prolonged According to the Inspired Pressure of Carbon Dioxide. Acta Anaesthesiologica Taiwanica, 42, 199-202.

[10] Arpino, D. (2020) Mindray A-Series Anesthesia Delivery System Consideration for Use as a Ventilator.

[11] Zbinden, A.M., Feigenwinter, P. and Hutmacher M. (1991) Fresh Gas Utilization Eightcircle Systems. British Journal of Anaesthesia, 67, 492-499.

https://doi.org/10.1093/bja/67.4.492

\section{Abbreviations}

ICU, Intensive Care Units;

$\mathrm{FiO}_{2}$, Fraction of Inspired Oxygen;

FGF, Fresh Gas Flow;

VHL, Virtual Health Library. 


\section{Appendix. Formula for Fresh Gas Flow Calculation}

Considering $x$ as the air flow, $y$ as the $\mathrm{O}_{2}$ flow, and $F i$ as the fraction of inspired oxygen, we will determine the $\mathrm{O}_{2}$ flow assuming that $F=$ fresh gas flow:

$$
0.21 x+y=F \cdot F i
$$

Knowing that $F$ is given by

$$
\begin{gathered}
x+y=F \\
x=F-y \\
0.21(F-y)+y=F \cdot F i \\
0.21 F-0.21 y+y=F \cdot F i \\
0.79 y=F \cdot F i-0.21 F \\
0.79 y=F \cdot(F i-0.21) \\
y=\frac{(F i-0.21) F}{0.79}
\end{gathered}
$$

Therefore, using (1) and (2), we get formula (3) which determines the $\mathrm{O}_{2}$ flow in terms of fraction of inspired oxygen and total gas flow.

$$
x=F-y \text { or }
$$

Using Equations (2) and (3), we conclude that the air flow is given by:

$$
x=\frac{F \cdot(1-F i)}{0.79}
$$

Some considerations are necessary for the use of formula (3). It is initially observed that if $F i=0.21(21 \%)$, then $y=0$, that is, there is no $\mathrm{O}_{2}$ flow.

If $F i$ is maximum, that is, $F i=1(100 \%)$, it follows the total flow that is equal to the $\mathrm{O}_{2}$ flow, which means that there is no gas other than $\mathrm{O}_{2}$. 